\title{
Covert trade in toxic vetch continues
}

Sir - The Commentary "A mess of red pottage" by two of us ${ }^{1}$ exposed the export from Australia of seeds from toxic common vetch (Vicia sativa) as a cheap substitute for the edible red lentil (Lens culinaris). Despite curbs to this trade in the wake of our article, the problem has recurred.

Dietary cyanoalanine neurotoxins from vetch accumulate in the brains and livers of pigs, rats and poultry. Effects on sulphur metabolism result in urinary excretion of cystathionine and accumulation of the non-functional glutathione analogue $\gamma$-glutamyl- $\beta$-cyanoalanyl-glycine. E. G. Brown ${ }^{2}$ pointed out that the genetic predisposition towards favism in Mediterranean communities makes this doubly unfortunate, because common vetch contains the favism toxin vicine.

After our Commentary was published, India and Egypt banned, and Saudi Arabia restricted, imports of vetch. The Victorian Weekly Times published articles entitled "Scientists cripple vetch industry" and "Vetch now unfit for humans to eat". The A $\$ 18$ million (US\$11.7 million) market collapsed.

But last year we were alerted by the Sri Lankan Health Department of the problem's re-emergence. Unlabelled bags of split red vetch (240 tonnes) had been exported from Adelaide via Johor in Malaysia to Colombo. On arrival, the container documentation had changed from "red split vetch" to "red split lentils". This event was extensively reported in the Sri Lankan Daily News ${ }^{3}$, but was ignored by the international media.

In April 1999, a report on Australian $\mathrm{ABC}$ radio $^{4}$ gave details of the multithousand tonne vetch/lentil substitution racket. The export price (A $\$ 340-400$ per tonne) leaves no doubt that the bulk is sold for human consumption. Exports (in tonnes) from South Australia for the first four months of 1999 include: split vetch to Yemen (22) and United Arab Emirates (194); and 'whole vetch' to Argentina (10), Bangladesh (989), Belgium (187), Germany (63), Italy (149), Japan (120), Mexico (40), The Netherlands (124), Pakistan (903), The Philippines (22), Portugal (106), South Africa (42) and Taiwan (86).

From these data, and the sale of unlabelled split red vetch in the markets of Pakistan and Bangladesh, we conclude that either it is being split in the importing country or it is being split in Australia and exported labelled as whole vetch.

When cooked (without leaching) in mistake for red lentils, 1,000 tonnes of vetch gives ten million 100-g platefuls, each containing $0.5 \mathrm{~g}$ of cyanoalanine toxins. The harmful effects of vetch consumption in animals are known, but the effects on humans are not. Most at risk are malnourished vegetarian societies with sulphur-deficient diets.

To protect a valuable and expanding lentil industry, the Australian government moved swiftly (7 April 1999) to declare both vetch and lentils as prescribed grains. This means that inspection and phytosanitary certification are mandatory before export. Unfortunately, the financial rewards to exporters and importers are still too high to eliminate this dishonest trade.

Max E. Tate ${ }^{\star}$, Jane Rathjen, Ian Delaere, Dirk Enneking

Department of Plant Science, University of Adelaide, Waite Campus, Glen Osmond, South Australia 5064 ${ }^{*}$ Visiting scientist

1. Tate, M. E. \& Enneking, D. Nature 359, 357-358 (1992).

2. Brown, E. G. Nature 360, 9 (1992).

3. http://www.lanka.net/lakehouse/archive.html (8 October 1998).

4. http://www.abc.net.au/rn/talks/8.30/helthrpt/stories/s22429.htm

\section{Valuable biodiversity data under threat}

Sir- Your report ${ }^{1}$ on the move by the Burke Museum of Natural History and Culture to become independent of the University of Washington, Seattle, because of a lack of financial support from the university, illustrates one of the threats facing university biodiversity collections.

The Burke museum has the advantage of size to make plausible its becoming an independent institution. But curators of smaller, yet important, collections often face a similar financial crunch that cannot be solved by becoming independent. They have the option of minimal management of the collections, sometimes through out-ofpocket support, or of allowing the collections to become orphaned.

If orphaned collections are not transferred to an institution interested in their care, the result is a tragic, irreplaceable loss of biodiversity data. That is certain to hasten the decline of university training in systematic biology, which depends on collections. These and other factors contribute to what is aptly called "the crumbling infrastructure of biodiversity" .

It is to be hoped that universities will recognize that their biodiversity collections are as important a component of the infrastructure for biological sciences as electron microscopes and ultracentrifuges. Angelo Capparella

Department of Biological Sciences, Illinois State University, Normal, Illinois 61790, USA

1. Dalton, R. Nature 399, 189 (1999).

2. Winker, K. Cons. Biol. 10, 703 (1996).

\section{Global e-journal must} \section{take radical approach}

Sir - Much nonsense has been written about the 'E-Biomed' initiative to launch a global website for much of the biomedical literature, announced by Harold Varmus, director of the US National Institutes of Health (NIH). If it were the case that the present system had served science well for 300 years, for example, the outrage over the present state of scientific publishing felt in some quarters would not exist (see Nature 398, 735 \& 399, 292; 1999).

Happily, dialogue has been under way worldwide for some time, involving people from various disciplines, to investigate how electronic publishing can reach the broadest possible audience. Some new model will emerge from this process. Harmonization of goals and means is difficult, and benefits greatly from the involvement of a broad pool of perspectives and contributions. In this setting, the Varmus initiative is welcome, as are the critical evaluations to which the proposal will be subject.

Some of the valid concerns are the preservation and organization of materials; cataloguing; provenance (whether to peer review); copyright; and economic impact (including access in less developed countries). To advance the 'E-Biomed' proposal, I suggest that a moderated listserver is set up to initiate documentation and development of the larger community of interest. The NIH would be an appropriate host. These groups should be encouraged to participate: authors and researchers; archivists and librarians; Internet specialists; publishers and professional organizations; and readers.

I am initially mistrustful of what appears to be (largely) an electronic replication of existing methods of publication. One possibility is that 'E-Biomed' could host papers vetted by 'alternative' editorial boards, whose composition would be publicly stated, and whose editorial manifesto would be published, but whose membership would not be controlled by a central governing board.

Lance Sultzbaugh

Elan Pharmaceuticals, 3760 Haven Avenue, Menlo Park, California 94025, USA 